\title{
The Relationship between Social Trust and Economic Development with Compilation Approach (Study Case: Baharestan County)
}

\author{
Ahmad Daghestani ${ }^{1}$.Davood Khoshekan ${ }^{2}$ and Azade Farhadi ${ }^{3}$ \\ ${ }^{1}$ Master of Communication Sciences, Quchan Branch, Islamic Azad University, Quchan, Iran \\ Daghestaniahmad2016@gmail.com \\ ${ }^{2}$ Master of Human Resource Management, PNU University of Tehran \\ Khoshshekan.d2016@gmail.com \\ ${ }^{3}$ Nursing Bachelor Student of Nursing Higher Education Centre, Quchan \\ Farhadiazade2015@gmail.com \\ *Corresponding Author Email: Daghestaniahmad2016@gmail.com
}

\section{Article history:}

Received date: 03 November, 2019

Review date: 21 December 2019

Accepted date:25 January 2020

\section{Keywords:}

Social Trust, Economic Development, Institutional Measures

\begin{abstract}
Social trust is one of the concepts that over the past two decades, researchers have looked at it from different perspectives. Social trust is one of the most important aspects of social relations and the underlie of social cooperation and partnership among the members of community. In the last decades, in economic studies done on social and cultural factors it has been much emphasized on development. The aim of this study is investigating the relationship between social trust and its components with economic development by compilation approach (including three theories: cultureoriented Marx Weber's Theory, Institutional Economic Theory and Institutionalism Robert Putnam Theory). Research method is Survey and questionnaire is used as the research tool. The results showed a high level of social trust in BAHARESTAN County. There is also a positive and significant relationship between social trust and institutional measures for development.
\end{abstract}

Please cite this article as: Daghestani A., Khoshekan D,. Farhadi A. 2020. The Relationship between Social Trust and Economic Development with Compilation Approach (Study Case: Baharestan County) KURMANJ; The Journal of Culture, Humanities and Social Science; 2(1): 11-15

\section{Introduction:}

The trust is the central concept in sociology classical theories and main theme of modern theories of social capital and the field of interaction and social relations. The trust can be considered as the most important order paradigm and oriented thoughts of sociologists such as Durkheim and Tonnies. However, the trust is substrate of interactions and social relationships and central concept of social capital. Nicolas Luhmann's have a functionalist look at the trust in terms of control and predict social action perspective. Especially in modern society which is along with the complexity, risk and risk-taking. In such circumstances, the trust plays an important role in determining and maintaining social order. Zetomga, Gidnez and Coleman also consider a positive role for social trust. In fact, the trust allows people to easily communicate with each other; the trust is considered as one of the most important dimensions of social capital by such facilitating interaction. In the past, scholars in the economic development field primarily emphasized on economic components but in the last years, more attention has been paid to the social and cultural factors of development. The trust concept plan is actually the growth of kind of cultural orientation and to Zetomka, apply the rotation is the difficult economic concepts to the soft cultural concepts. Development thinkers consider difficult the cultural and social development without social trust and say the factors such as trust are important behavioral patterns result in overall productivity of the community and can develop the prosperity and the production. In this study, using an integrated approach approach (including three theories: cultureoriented Marx Weber's Theory, Institutional Economic Theory and Institutionalism Robert Putnam Theory) the relationship between social trust and economic development in BAHARESTAN County is studied. Two variables of social trust and economic development are used to investigate this relationship; each of these variables has also special characteristics. Social trust variable has three components: "Trust in the 
organizations", "trust in the employments" and "political trust". Trust in the organizations is so important since the organization's legitimacy depends on people's confidence in the organizations. Trust to business is essential to sustain the public life. The political trust means the trust in institutions and offices that are directly associated with political power. Economic development variable also has the variables such as readiness to invest efficiency and productivity, information sharing, innovation, entrepreneurs and reduce the cost of transactions.

\section{Theoretical Fundamentals of Research:}

Trust is in fact a positive attitude to the person or foreign something and evaluates a phenomena that we are face with it. Coleman believes that the trust is a quality of the relationship that has at least two sides: someone who trusts and trustee. He says both of them have the purposes, the purpose of providing the benefits. But Zetompca defines the trust a betting based on the action of others in the future. Luman believes that the trust is associated with the concept of risk and it is proposed recently. He studies about the trust function within the social system and compares it with the function of law in the society. He believes that trust function in the social system is to reduce the social uncertainty and thus increase the ability to predict the behaviors. Eric Aslaner in another classification, puts the trust in both experimental and ethical group and believes that empirical trust is based on knowledge and understanding of risk related to those who already know them. But ethical trust as a foundation of public trust is related to those who we do not recognize them. Oufe has raised types of social trust: 1- Citizens' trust in their fellow citizens or subcategory of "others' world" and 2- Citizens' trust in political elites or elites of the other parts (such as representatives of the churches, the media, the police, the court system or physician), 3- elites' trust to each other and to the elites to elite of the other parts such as business, labor, religious, academic, military parts etc. 4- trust the High levels of community to low levels one. However, most studies have focused on the second domain of the trust relationships, but Oufe emphasizes on horizontal trust among non-elites. It has been used an integrated approach consists of three theories in theoretical framework of this study. Marx Weber is the first sociologist who has explained the relationship between the values and development and talked about the impact of culture and cultural elements at the beginning and continuity of the development. He has been effective in pointing out the values and institutions in the economy and influencing factors such as the North's economic approach has been influenced by him. Economic institutionalism approach; he criticizes the conventional and dominant economic theories due to the neglect of social and political structures and too much analysis and cares to the role of intentions, motivations, ideological beliefs and attitudes of people in their economic behavior. Institutionalisms are the critics of classical economic that summary everything in the market system but institutional economic believes that the market system is only one institution among many other institutions with mutual relations with them and study about the economic behavior in his cultural environment. Nors says: "Institutions and incentive structures resulted by the society institutions is the main cause of development or the lack of development of the countries and different reactions of economic actors is a reflection of the prevailing institutional conditions on the society. He states that the institutions determine the conditions of economic activities in the society and pay attention to the principle of institutional performance. As a result in the approach of the institutional economy the key concepts such as groups, social networks, trust and values have been considered and express the economists' positive view to cultural and social components of development. These components are the factors reducing transaction costs in economic activities and in this condition, ready invests increase the efficiency and effectiveness of economic activities. Therefore, from the perspective of institutional economic approach, people reasonably invest to maximize the efficiency of productivity in trust and participation in social capital. In fact, the trust is a social catalyst that lubricates the wheels of social and economic exchanges and these exchanges are very expensive, time-consuming and bureaucratic in the absence of it. Putnam studies about the social capital in economic development. He has studied the impact of social capital in strengthening civil society and effective democracy on one hand and economic growth on the other hand. Putnam also did a research using the comparative- history method in Italy for 20 years and found that northern regions are more advanced rather than the southern regions. He points out the indices such as civic participation, political equality, solidarity, trust and social structures of cooperation and concluded that social capital and its components can be explained and clarified by differences in terms of economic development 


\section{Research Method:}

In this study data are collect using survey and questionnaires methods. The questions are designed in a manner of very low, low, kind of, high, very high and answer of any questions is placed on a Likert Scale. The collected data is processed using the software SPSS software. The statistical population of this study (450 people) using Cochran formula has been selected among the people between in ages of 15-65 years old (active population) living in Baharestan County.

Table 1: Frequency distribution and the mean of social trust components

Institutional measures for the development include six components: Preparation for the investment, information exchange, innovation, increasing the efficiency, reducing the costs of transactions and preparing for paying the taxes and insurance. The results of the frequency distribution and mean of these variables are.

\section{Findings}

In Table (1) the esults related to the level of social trust in Baharestan County which contains three components of "trust in the organizations", "trust in the employments" and "political trust" (Each of these components are also included some indecis) is analyzed. As it can be seen, the level of social trust is different to the different jobs. For example, the findings showed that the level of social trust with an mean of 91.25 is in the first place among the other components of social trust 91.25 in the university professors. The lowest level of social trust is related to the entrepreneurs and merchants. As well as the number of those who have low political trust are more than number of those who have high political trust. Generally, the mean of social trust is $0.71 \%$ and higher than the assumed mean 0.60 per cent in Likert scale.

\begin{tabular}{lllllll}
\hline mean & Very low & low & Kind of & high & Very high & Components of social trust \\
\hline 56 & 30 & 110 & 125 & 115 & 70 & trust in MPs \\
\hline 58 & 40 & 85 & 115 & 160 & 50 & trust in courts and judges \\
\hline 47.5 & 45 & 100 & 153 & 89 & 68 & trust in politicians \\
\hline 79 & 14 & 25 & 49 & 190 & 172 & trust in the police \\
\hline 68 & 52 & 74 & 109 & 117 & 98 & trust in the Clergymen \\
\hline 74.5 & 25 & 33 & 113 & 164 & 115 & trust in doctors \\
\hline 91.25 & 2 & 16 & 61 & 172 & 199 & trust in university professors and teachers \\
\hline 47.5 & 57 & 90 & 150 & 125 & 28 & trust in shopkeepers and market \\
\hline 70 & 10 & 43 & 175 & 142 & 80 & trust in the media \\
\hline 64.5 & 14 & 78 & 159 & 110 & 89 & trust in the Iranian Revolutionary Guards \\
\hline 81 & 9 & 67 & 110 & 104 & 160 & trust in athletes \\
\hline 80 & 28 & 58 & 65 & 179 & 120 & trust in the workers \\
\hline 35 & 125 & 198 & 55 & 43 & 29 & trust in entrepreneurs \\
\hline 53.5 & 32 & 77 & 155 & 111 & 75 & trust in the military \\
\hline
\end{tabular}

\section{Table 1: Frequency distribution and the mean of social trust components:}

Institutional measures for the development include six components: Preparation for the investment, information exchange, innovation, increasing the efficiency, reducing the costs of transactions and preparing for paying the taxes and insurance. The results of the frequency distribution and mean of these variables are shown in Table (2). Generally, the mean of total institutional measures for the development is 76.31and higher than the assumed mean 0.60 in the Likert Scale. 


\begin{tabular}{lllllll}
\hline mean & Very low & low & Kind of & high & Very high & Components of institutional measures for development \\
\hline 76.5 & 35 & 30 & 89 & 215 & 76 & Preparation for the investment \\
\hline 85 & 15 & 30 & 69 & 208 & 96 & increasing the efficiency \\
\hline 89.5 & 9 & 25 & 36 & 241 & 112 & information exchange \\
\hline 76.5 & 20 & 41 & 82 & 230 & 75 & reducing the costs of transactions \\
\hline 73 & 32 & 44 & 105 & 200 & 70 & innovation \\
\hline 76.5 & 23 & 51 & 84 & 202 & 79 & preparing for paying the taxes and insurance
\end{tabular}

Table 2: The frequency distribution and the rating mean of institutional measures components for development of economy

In this study, Pearson correlation coefficient is used in order to study the relationship between social trust and institutional measures for development and its components. The results have been show in Table 3.

\begin{tabular}{|c|c|c|c|}
\hline Significance level & Correlation value & components & Variable \\
\hline 0.001 & 0.43 & Preparation for the investment & \\
\hline 0.028 & 0.120 & information exchange & \\
\hline 0.003 & 0.170 & efficiency & \\
\hline 0.001 & 0.312 & innovation & \multirow{3}{*}{ Social trust } \\
\hline 0.014 & 0.130 & reducing the costs of transactions & \\
\hline 0.001 & 0.268 & preparing for paying the taxes and insurance & \\
\hline
\end{tabular}

Table 3: The results of the correlation coefficient between social trust and the final measures and its components

As it can be seen in the above table, in studying the relationship between social trust and institutional measures for all variables and all of its variables p- value is less than 0.05 for all the variables. Therefore, it can be concluded that there is a significant relationship between the individual components of institutional measures and social trust.

\section{Conclusion:}

Social trust is one of the most important aspects of human relationships that are underline of participation and cooperation among members in the society. Trust is considered as the basic preconditions for economic, social, cultural and political development in any society. The purpose of this study is investigating the relationship between social trust and its components with economic development by compilation approach (including three theories: culture-oriented Marx Weber's Theory, Institutional Economic Theory and Institutionalism Robert Putnam Theory) in Baharestan County. For this purpose, the components and indices of social trust and its relationship with economic development in the county have been analyzed. The results of this study show that the mean of social trust in groups, organizations and businesses are different. The studies done showed that the trust in teachers and university professors, law enforcement and police is higher than the assumed mean $(0.60)$ that it indicates the appropriate cultural and social context for the development in this county. The trust in businessmen and merchants and real estate and car agencies and is lower than assumed mean. On the other hand, there is a significant relationship between the individual components of institutional measures and social trust. The results also show that the citizens' behavior in Baharestan County is very good in the measures such as being ready to invest in and readiness to pay the taxes due to high security systems and appropriate cultural richness. 


\section{References:}

Abaszade M. (2009), "Factors affecting the development of students' trust", Social Welfare Journal, No. 15 Adhami J. (2007), "Trust among people", MA Thesis, Teacher Training University

Colman J. 1998, "Foundation of Social Theories", Translated by Sabouri M. Tehran, NEY Publication

Field J. (2007), "Social Capital", Translated by Ghafari G. and Ramezani H. Tehran, Kavir Publication

Luhmann, Niklas, Trust and power: tow works by Nicolas Luhmann, Chichester [etc.]: Wiley, pitman press, 1979

Motevaseli M. (2005), "Economic Development, Concepts, principles and approaches", Tehran, SAMT Publication

North, Douglass C. (2005).Understanding the process of conomic change princton. princton university press

Putnam, D. Robert Bowling alone: The collapse and Revival of American Community New York: Simon and Schuster, 2000

Solow, Robert ( 2001). Notes on Social capital and economic Performance. Washington: The World Bank

Sztompka, pioter. Trust: A sociological Theory. Port chester, NY. USA: Cambridge University Press. University Press, 2000

Tafaoli F. (1996), "History of economic beliefs", Tehran, NEY Publication

Tajbakhsh K. (2005), "Social capital "trust, democracy and development", Translated by Khakbaz A. and Pouyan H. Tehran, Shiraze Publication 